\title{
Soft tissue pathosis associated with asymptomatic impacted lower third molars
}

\author{
Göksel Şimşek-Kaya ${ }^{1}$, Elvan Özbek ${ }^{2}$, Yıldıray Kalkan ${ }^{3}$, Günay Yapıcı ${ }^{4}$, Ertunç Dayı ${ }^{5}$, Tuba Demirci ${ }^{6}$
}

${ }^{1}$ Assistant Professor, Department of Oral and Maxillofacial Surgery, Faculty of Dentistry, Atatürk University

${ }^{2}$ Professor, Department of Histology and Embryology, Faculty of Medicine, Atatürk University

${ }^{3}$ Assistant Professor, Department of Histology and Embryology, Faculty of Medicine, Rize University

${ }^{4}$ Research Assistant, Department of Oral and Maxillofacial Surgery, Faculty of Dentistry, Atatürk University

${ }^{5}$ Professor, Department of Oral and Maxillofacial Surgery, Faculty of Dentistry, Atatürk University

${ }^{6}$ Research Assistant, Department of Histology and Embryology, Faculty of Medicine, Atatürk University

Correspondence:

Department of Oral and Maxillofacial Surgery,

Faculty of Dentistry,

Atatürk University,

25240, Erzurum (Turkey)

gokselsimsek@yahoo.com

Received: 02/06/2010

Accepted: $14 / 11 / 2010$

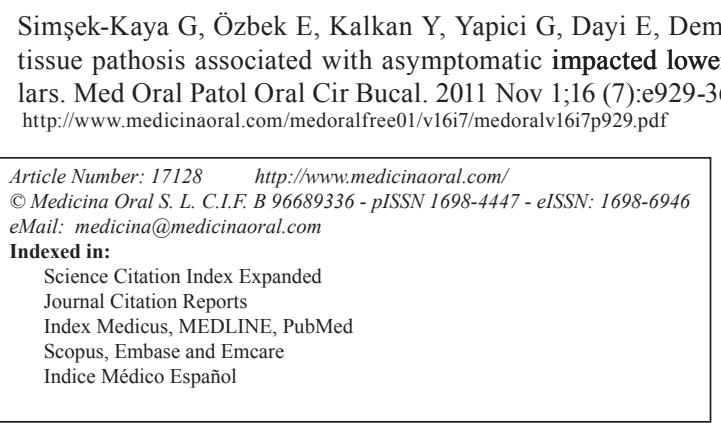

\begin{abstract}
Objective: The aim of this study was to identify the prevalence of pathological changes in the pericoronal tissue of asymptomatic impacted lower third molars and to assess the correlation between pathological changes and patient demographic, radiographic and morphological characteristics.

Study Design: Follicles associated with fully impacted lower third molars were submitted for histological examination after surgical extraction from 50 patients. The correlation between pathological changes in the dental follicle and age, gender, depth of impaction, angular position, and coverage and tooth development was analyzed.

Results: Cystic changes were observed in $10 \%$ of specimens and inflammatory changes in $62 \%$. Incidence of pathological changes was significantly higher in Class B impacted teeth when compared to Class C impacted teeth. A significant correlation was found between epithelial cell activity and the completion of tooth development.

Conclusion: We recommend monitoring all third molars whether or not they are symptomatic and conducting histopathological analyses on all surgically extracted follicle tissue.
\end{abstract}

Key words: Impacted lower third molar, pericoronel tissue, radiograph, pathology.

\section{Introduction}

Tooth formation occurs in the development sac, also known as a dental follicle (DF) or dental sac (DS) that surrounds the dental papilla and enamel organ (1). The DF is responsible for coordinating resorption and deposition in the bone opposite the region of eruption through intraosseous movement (2) and is also responsible for the structure of the periodontal ligament and cement $(1,3)$. Despite this important role in eruption physiology, previous studies have reported that the DF may undergo cystic degeneration and/or neoplastic transformation (1, 4-7). The DF appears radiographically as a pericoronal radiolucency, the width of which is of the utmost importance in identifying DF pathology (3). Previous studies 
have suggested that a pericoronal radiolucency $2.5 \mathrm{~mm}$ or larger on a panoramic radiograph may indicate an abnormality (4-8).

Extraction of impacted mandibular (lower) third molars (ILTMs) is one of the most frequent procedures performed by oral and maxillofacial surgeons $(6,8-12)$. Because most dental practitioners discard extracted unerupted third molars rather than send them for histopathological analysis, no accurate information is available regarding the prevalence of pathological formations (9). While there is a consensus that ILTMs should be extracted when pathological changes and serious clinical symptoms are observed, there is no agreement regarding the prophylactic extraction of ILTMs (810,13). As a result, some clinicians espouse prophylactic extraction, while others favor observation and periodic monitoring $(6,9,10,13)$.

The aim of this study was to determine the prevalence of pathological changes in the pericoronal tissue of clinically and radiographically asymptomatic lower third molars and to assess the correlation between pathological changes and various patient demographic, radiographic and morphological characteristics.

\section{Materials and Methods}

This study was approved by the Ethics Committee of the Atatürk University Faculty of Dentistry, and all participants gave their informed consent. Patients were selected from among those visiting our clinic for removal of asymptomatic ILTMs fully impacted and with follicular spaces smaller than $2.5 \mathrm{~mm}$, over a period of ten months, from January 2009 to November 2009. Only patients who were in good medical health and had not taken any drugs for 30 days before surgery were included. Patients with any signs or history of infection or impacted mandibular third molars with a widened pericoronal region were excluded. From a total of 978 patients, 50 were selected. For the study, only 1 tooth was surgically extracted, even if both third molars required extraction.

Radiographic analysis was conducted using panoramic radiographs (OPTs). All images were exposed for $0.2 \mathrm{~s}$ using an Evaluation X 3000-2C x-ray unit (New Life Radiology $\mathrm{Srl}$, Grugliasco, Turin, Italy) operated at $70 \mathrm{kVp}$ and $8 \mathrm{~mA}$ with a focus-receptor distance of $30 \mathrm{~cm}$. All images were exposed to $60-80 \mathrm{kV}$ and 1-10 $\mathrm{mA}$ from an x-ray unit (Marita, MFG Corp., Kyoto, Japan) for 16.2 $\mathrm{s}$ with three rotation centers and a constant magnification of $x 1.3$. The pericoronal space was measured from the mesial, distal and occlusal surfaces, and the largest width was recorded. The follicular space was measured from panoramic radiographs independently by the three authors, and the largest width was recorded, disregarding the manufacturer's reported magnification factor.

The depth of the ILTM impaction was recorded accord- ing to Nordenram (14), as follows: Class A (high occlusal level), the most superficial part of the third molar is located on a level with the occlusal plane; Class B (medium occlusal level), the most superficial part of the third molar is located between the occlusal plane and the cement-enamel junction of the second mandibular molar; and Class C (Deep occlusal level), the most superficial part of the third molar is located apically to the cement-enamel junction of the second mandibular molar. (Since this study included only fully impacted third molars, no Class A teeth were included.) Third molar angulation was determined according to Shiller (15), as follows: vertical (V), $0-10^{\circ}$; mesioangular $(\mathrm{M})$ or distoangular (D), $11^{\circ}-70^{\circ}$; horizontal $(\mathrm{H}), \geq 71^{\circ}$; and a group of cases with inverted or buccolingual angulation were combined as inverted (I). Third molar development was estimated using Kohler et al.'s (16) modification of the method described by Gleiser and Hunt (17). Only teeth between Phase 7 (root 3/4 calcified) and Phase 10 (complete root formation, root canals terminally convergent) were included in the study. Molar coverage was classified as either total mucosa, or partial bone coverage or total bone coverage.

Extractions were performed under local anesthesia without any kind of sedation (oral, nasal or venous) and were standardized to as great an extent as possible. Articaine $\mathrm{HCl} 2.5 \%$ plus 1:100,000 epinephrine (Ultracaine D-S Forte Ampul; Aventis, Istanbul, Turkey) was used for the inferior alveolar and buccal nerve blocks. A standard incision was used, from the anterior border of the ramus to the distobuccal corner of the second molar, following the buccal gingival sulcus along the second molar. A vertical incision was made from the mesiobuccal corner of the second molar to the mucogingival line. After periosteal elevation, bone on the buccal and distal sites was removed with a round bur using abundant saline irrigation. In all cases, the third molar was carefully extracted. Following the extraction, the pericoronal tissue was carefully curetted, and the soft tissue was sent for histopathological analysis. Closure was done with 3-4/0 silk sutures. Tissue samples were immersed in $10 \%$ neutral-buffered formaldehyde for 48-52 hours and dehydrated using a graded ethanol series. Samples were embedded in paraffin wax, serially sectioned into 5- $\mu \mathrm{m}$ slices using a Leica RM2125RT microtome (Leica, Germany) and mounted on glass slides. The prepared sections were stained with hematoxylin and eosin (H\&E) and examined under a Nikon Eclipse E600 light microscope (Nikon, Japan) equipped with a digital color camera attachment (Nikon DS-Fil, Japan). Slides were viewed independently by three histologists. Diagnoses were recorded when all three histologists were in agreement. In cases of disagreement, a consensus diagnosis was recorded after a joint review. Specimens were classified as cystic if they showed a 
dense fibrous connective tissue wall lined with several layers of stratified squamous epithelium (6). Epithelial cell activity was recorded as follows: inactive (less than 20 layers of epithelial cells and no epithelial projections into the connective tissue), hyperplasic (more than 20 layers and/or epithelial projections) or absent (no epithelial cells observed) (1). Connective tissue was classified as dense or loose. Inflammation was classified as acute, chronic or absent. Calcification was recorded as either present or absent.

Histopathological data was analyzed according to the radiographic criteria described above and by gender and age, with patients aged 25 years or younger in one group and patients older than 25 years of age in another group. A chi-square test was conducted with gender, age and radiographic findings as independent variables and histopathological parameters as dependent variables (Statistical Analysis System, Windows Ver. 9.0, Cary, NC, USA). If the number of observations was insufficient, Fisher's exact test was applied. The level of significance was set at $\mathrm{p}<0.05$.

\section{Results}

Of the 50 patients included in the study, $56 \%$ were female $(\mathrm{n}=28)$, and $44 \%$ were male $(\mathrm{n}=22)$. Mean age was $20.97 \pm 1.96$ (age range 16-25) in the 25 years or younger age group $(\mathrm{n}=31)$ and $33.00 \pm 8.76$ (age range: $26-59)$ in the 25 and older age group $(\mathrm{n}=19)$. Mean age for women and for men was $24.71 \pm 6.32$ (16-45) and $26.59 \pm 9.95$ (16-59), respectively.

Correlations between ILTM pathology and demographic factors are given in (Table 1), and correlations between ILTM pathology and radiographic and morphological factors are given in (Table 2).

Cystic changes were found in $10 \%(n=5)$ of specimens. Eighty percent of the cystic changes $(n=4)$ were in the younger age group; the differences between younger and older patients was not statistically significant. Cystic changes were also seen in 4 female patients and 1 male patient, but again, this difference was not statistically significant. No correlation was found between cystic change and depth of impaction. Two out of 17 mesioangular teeth $(11.8 \%), 1$ out of 8 distoangular

Table 1. Histopathological findings according to patient age and gender.

\begin{tabular}{|c|c|c|c|c|c|}
\hline & & \multicolumn{2}{|c|}{ Age } & \multicolumn{2}{|c|}{ Sex } \\
\hline $\begin{array}{c}\text { Histopathological } \\
\text { Features }\end{array}$ & Subclass & $\leq 25$ years $(n=31)$ & $>25$ years $(n=19)$ & $F(n=28)$ & $M(n=22)$ \\
\hline \multirow{4}{*}{ Cell Activity } & Absent & 5 & 3 & 4 & 4 \\
\hline & Hyperactive & 15 & 14 & 19 & 10 \\
\hline & Inactive & 11 & 2 & 5 & 8 \\
\hline & $\left(X^{2} ; p\right)$ & \multicolumn{2}{|c|}{$4.1 ; 0.13$} & \multicolumn{2}{|c|}{$2.8 ; 0.25$} \\
\hline \multirow{4}{*}{ Inflammation } & Absent & 13 & 6 & 11 & 8 \\
\hline & Acute & 3 & 1 & 4 & 0 \\
\hline & Chronic & 15 & 12 & 13 & 14 \\
\hline & $\left(X^{2} ; p\right)$ & \multicolumn{2}{|c|}{$1.1 ; 0.58$} & \multicolumn{2}{|c|}{$3.9 ; 0.15$} \\
\hline \multirow{6}{*}{ Connective tissue } & Dense & 6 & 3 & 6 & 3 \\
\hline & Loose & 25 & 16 & 22 & 19 \\
\hline & $\left(X^{2} ; p\right)$ & \multicolumn{2}{|c|}{$0.1 ; 0.75$} & \multicolumn{2}{|c|}{$0.5 ; 0.48$} \\
\hline & Absent & 31 & 18 & 27 & 22 \\
\hline & Present & 0 & 1 & 1 & 0 \\
\hline & $\left(X^{2} ; p\right)$ & \multicolumn{2}{|c|}{$1.7 ; 0.20$} & \multicolumn{2}{|c|}{$0.8 ; 0.37$} \\
\hline \multirow{3}{*}{ Cyst } & Absent & 27 & 18 & 24 & 21 \\
\hline & Present & 4 & 1 & 4 & 1 \\
\hline & $\left(X^{2} ; p\right)$ & \multicolumn{2}{|c|}{$0.8 ; 0.38$} & \multicolumn{2}{|c|}{$1.3 ; 0.25$} \\
\hline
\end{tabular}


Table 2. Histopathological findings according to radiographic features of the third molar.

\begin{tabular}{|c|c|c|c|c|c|c|c|c|c|c|c|c|}
\hline \multirow[b]{3}{*}{$\begin{array}{c}\text { Histopathological } \\
\text { Features }\end{array}$} & \multirow[b]{3}{*}{ Subclass } & \multicolumn{11}{|c|}{ Radiographic Features } \\
\hline & & \multicolumn{2}{|c|}{ Depth $^{1}$} & \multicolumn{4}{|c|}{ Angulation $^{2}$} & \multicolumn{3}{|c|}{ Coverage $^{3}$} & \multicolumn{2}{|c|}{$\begin{array}{c}\text { Tooth } \\
\text { Development }\end{array}$} \\
\hline & & $\mathrm{B}$ & $\mathrm{C}$ & MA & DA & $\mathrm{H}$ & V & $\mathrm{BC}$ & $\mathrm{MC}$ & $\mathrm{MBC}$ & $\mathrm{C}$ & IC \\
\hline \multirow{4}{*}{ Cell Activity } & Absent & 7 & 1 & 2 & 4 & 2 & 0 & 3 & 1 & 4 & 3 & 5 \\
\hline & $\begin{array}{c}\text { Hyperactiv } \\
\text { e }\end{array}$ & 26 & 3 & 11 & 2 & $\begin{array}{l}1 \\
0\end{array}$ & 6 & 9 & 7 & 13 & 22 & 7 \\
\hline & Inactive & 10 & 3 & 4 & 2 & 6 & 1 & 17 & 0 & 6 & 5 & 8 \\
\hline & $\left(\mathrm{X}^{2} ; \mathrm{p}\right)$ & \multicolumn{2}{|c|}{$1.2 ; 0.54$} & \multicolumn{4}{|c|}{$10.7 ; 0.09$} & \multicolumn{3}{|c|}{$4.6 ; 0.33$} & \multicolumn{2}{|c|}{$7.2 ; 0.03$} \\
\hline \multirow{4}{*}{ Inflammation } & Absent & 13 & 6 & 5 & 5 & 8 & 1 & 12 & 1 & 6 & 9 & 1 \\
\hline & Acute & 4 & 0 & 2 & 0 & 1 & 1 & 2 & 0 & 2 & 3 & 1 \\
\hline & Chronic & 26 & 1 & 10 & 3 & 9 & 5 & 5 & 7 & 15 & 18 & 9 \\
\hline & $\left(X^{2} ; p\right)$ & \multicolumn{2}{|c|}{$7.9 ; 0.02$} & \multicolumn{4}{|c|}{$5.2 ; 0.52$} & \multicolumn{3}{|c|}{$11.1 ; 0.03$} & \multicolumn{2}{|c|}{$2.1 ; 0.34$} \\
\hline \multirow{3}{*}{ Connective tissue } & Dense & 8 & 1 & 3 & 2 & 1 & 3 & 5 & 1 & 3 & 5 & 4 \\
\hline & Loose & 35 & 6 & 14 & 16 & $\begin{array}{l}1 \\
7\end{array}$ & 4 & 14 & 7 & 20 & 25 & 16 \\
\hline & $\left(X^{2} ; p\right)$ & \multicolumn{2}{|c|}{$0.1 ; 0.78$} & \multicolumn{4}{|c|}{$5.9 ; 0.17$} & \multicolumn{3}{|c|}{$1.4 ; 0.49$} & \multicolumn{2}{|c|}{$0.1 ; 0.76$} \\
\hline \multirow{3}{*}{ Calcification } & Absent & 42 & 7 & 16 & 8 & $\begin{array}{l}1 \\
8\end{array}$ & 7 & 19 & 7 & 23 & 29 & 20 \\
\hline & Present & 1 & 0 & 1 & 0 & 0 & 0 & 0 & 1 & 0 & 1 & 0 \\
\hline & $\left(X^{2} ; p\right)$ & \multicolumn{2}{|c|}{$0.2 ; 0.68$} & \multicolumn{4}{|c|}{$2.0 ; 0.58$} & \multicolumn{3}{|c|}{$5.3 ; 0.07$} & \multicolumn{2}{|c|}{$0.7 ; 0.40$} \\
\hline \multirow{3}{*}{ Cyst } & Absent & 39 & 6 & 15 & 7 & $\begin{array}{l}1 \\
7\end{array}$ & 6 & 15 & 8 & 22 & 27 & 18 \\
\hline & Present & 4 & 1 & 2 & 1 & 1 & 1 & 4 & 0 & 1 & 3 & 2 \\
\hline & $\left(X^{2} ; p\right)$ & \multicolumn{2}{|c|}{$0.3 ; 0.57$} & \multicolumn{4}{|c|}{$0.7 ; 0.88$} & & $4.3 ; 0$ & & \multicolumn{2}{|c|}{$0.00 ; 1.00$} \\
\hline
\end{tabular}

DF; Dental Follicle.

1B; Class B, C; Class C.

2MA; Mesioangular, DA; Distoangular, H; Horizontal, V; Vertical.

3BC; Bone Coverage, MC; Mucosa Coverage, MBC; Mucosa and Bone Coverage.

4C; Complete, IC; Incomplete.

teeth (12.5\%), 1 out of 18 horizontal teeth $(5.6 \%)$ and 1 out of 7 vertical teeth (14.3\%) exhibited cystic changes; however, the differences between teeth of different angulation were not statistically significant. Moreover, no statistically significant differences were seen between cystic change and tooth coverage or development (Fig. 1).

Inflammatory changes were found in $62 \%(\mathrm{n}=31)$ of the specimens; $58.06 \%$ of the inflammatory changes $(\mathrm{n}=18)$ were in the younger age group. The difference between age groups was not statistically significant. Inflammatory changes were seen in 17 female patients $(54.84 \%)$ and in 14 male patients (45.16\%), but again, the differences between the women and men were not statistically significant. A statistically significant correlation was found between inflammation and depth of impaction $(\mathrm{p}=0.02)$, with the incidence of inflammation higher among Class C ILTMs in comparison to Class B ILTMs. There was also a statistically significant correlation between inflammation and coverage $(p=0.03)$, with 7 out of 8 ILTMs (87.5\%) covered by mucosa, 17 out of 23 ILTMs (73.9\%) partially covered by bone and 7 out of 19 ILTMS (36.8\%) completely covered by bone exhibiting inflammatory changes. The majority of teeth with inflammation (38.7\%) had mesioangular angulation, followed by those with horizontal angulation (32.3\%), vertical angulation (19.4\%) and distoangular angulation (68\%); however, the differences between inflammation rates by angulation were not statistically significant. Moreover, no correlation was found between inflammation and tooth development (Fig. 2).

No correlation was found between epithelial cell activity and age, gender, depth of impaction, angulation or coverage; however, a statistically significant correlation 


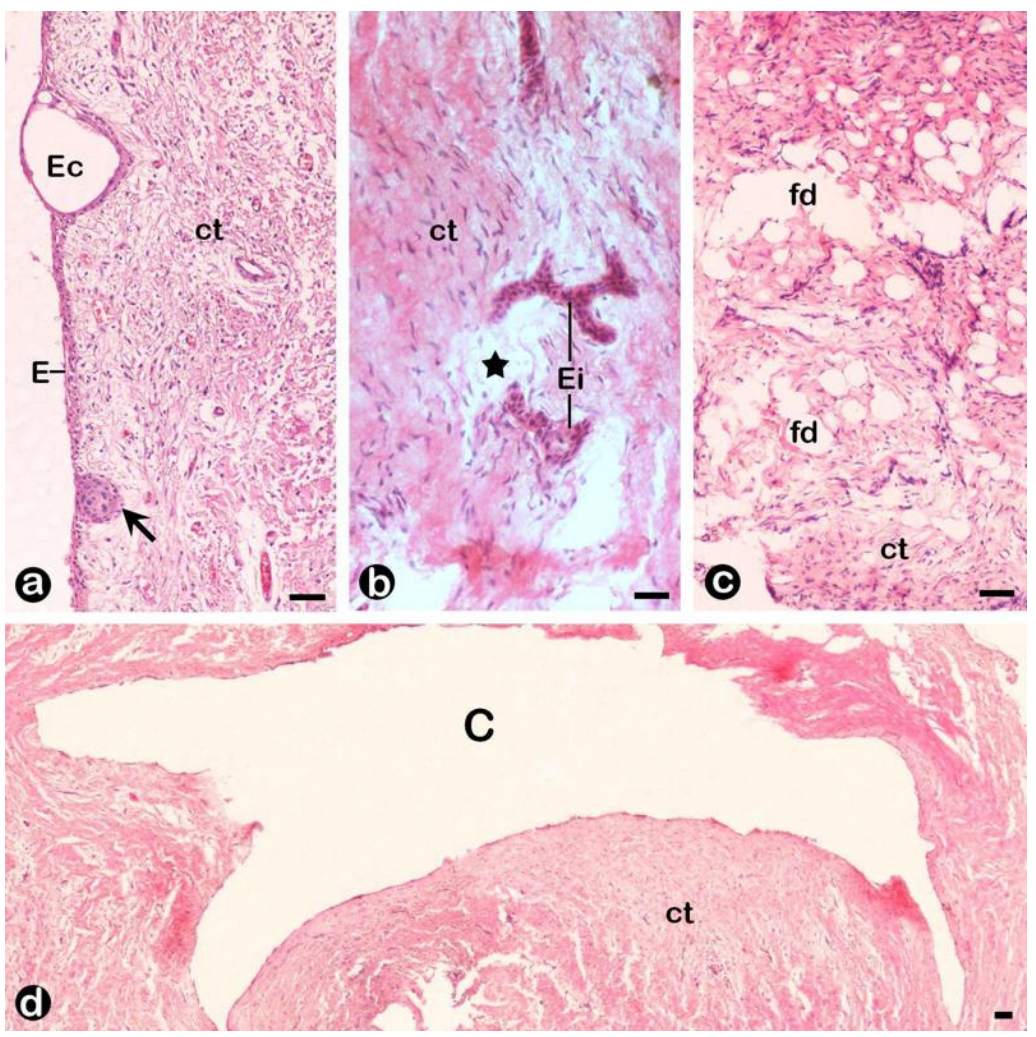

Fig. 1. Light microscopy photographs of a dental follicle.

E: epithelium, Ec: an intraepithelial cyst, arrow: epithelial cell proliferation with a globular appearance, Ei: epithelial cell islands within the connective tissue, asterisk: stromal edema, fd: fatty degeneration, C: a large cyst, ct: connective tissue. Stain: H\&E. Bars = $70 \mu \mathrm{m}$.

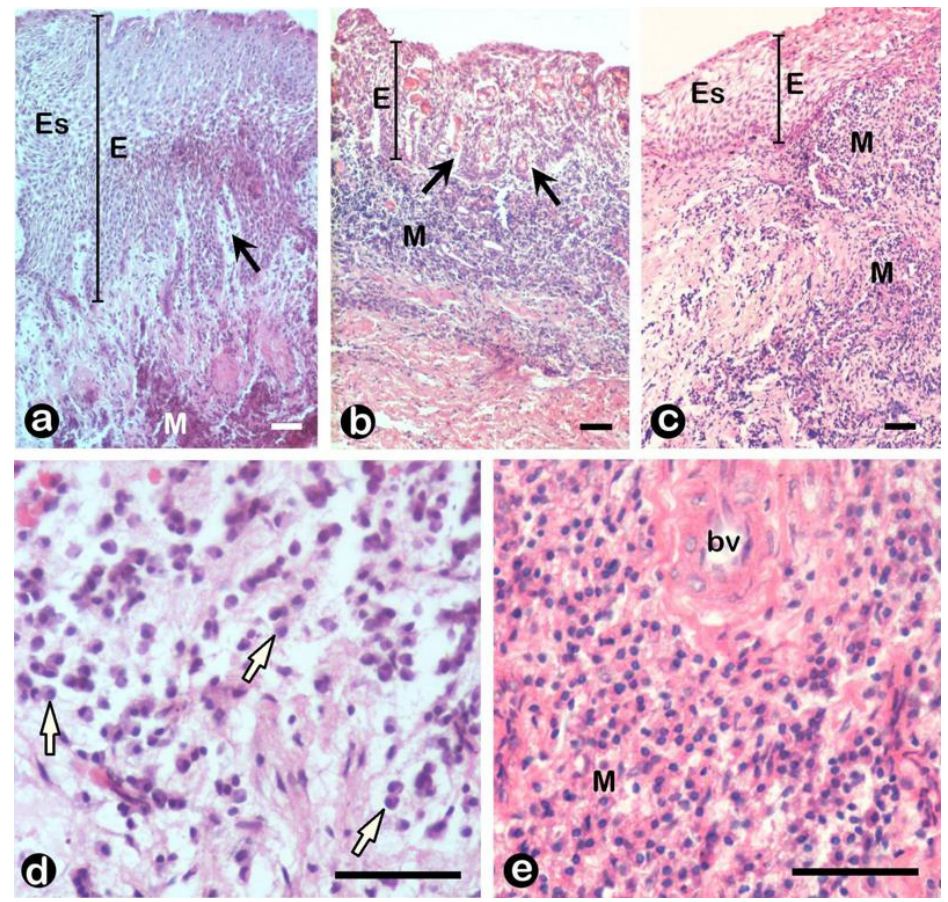

Fig. 2. Light microscopy photographs of a dental follicle.

E: epithelium, Es: epithelial swelling, M: mononuclear infiltrations within the connective tissue, by: blood vessel, black arrow: finger-like projections of subepithelial connective tissue, white arrow: plasma cells. Stain: H\&E. Bars $=70 \mu \mathrm{m}$. 
was found between cellular activity and tooth development ( $\mathrm{p}=0.03)$, (Fig. 1).

No correlation was observed between connective tissue density and any of the parameters examined (Fig. 2).

No correlation was observed between calcification and any of the parameters examined. Calcification was seen in only 1 patient (female, under age 25).

No correlation was observed between tooth coverage and any of the parameters examined.

\section{Discussion}

Prophylactic extraction of all ILTMs is reported to occur at rates of between $18 \%$ and $54 \%(10,18)$, although not all ILTMs cause clinical problems and the percentage of ILTMs that may remain asymptomatic for years is unknown (13). Prophylactic extraction is favored by many surgeons for reasons that include the possibility of pathological change $(8,10)$, the rise in surgical and postsurgical complications with age $(1,7,9)$, the higher costs of extraction if performed after pathology has developed and the quick rate of progression of untreated pathological conditions (9).

Most previous studies relied on radiographic analysis of the dental follicle to identify the presence of pathology (19-21). Radiographic studies have reported cyst development in impacted third molars to occur at rates of between $1 \%$ and $1.6 \%$ and epidemiological studies at rates of between $0.0002 \%$ and $2.31 \%(18,21-23)$. However, radiographic and clinical analysis of DFs may not always agree with histopathological findings (4,5, 7-9), and the absence of symptoms does not necessarily imply the absence of pathology (9). A follicular width greater than 2 $\mathrm{mm}$ on periapical radiographs (24) and $2.5 \mathrm{~mm}$ on panoramic radiographs has been suggested as an indication of DF pathology in asymptomatic impacted third molars (25). Miller and Bean (26) suggested that disease may be present in minute follicular spaces whereas areas of enlarged radiolucency may be histologically normal, making biopsy imperative. In our study, histopathological analysis showed cystic changes in $10 \%$ of ILTMs that were radiographically normal, and previous studies have reported much higher discrepancies (between 23\% and $70.5 \%)(4-9,11)$ (Table 3).
Our study found all pathological changes of ILTMs to be more frequent among women. Differences in male/ female ratios have also been reported in earlier studies, although the reason for this difference remains unknown (6-9).

In line with studies suggesting that pathological change occurs more frequently after age 20 and is particularly high among individuals aged 20-30 $(4,8,11,12)$, our study found $80 \%$ of cystic changes and $58.06 \%$ of inflammation occurred in patients aged 20-24. This result is consistent with the previous reports. Therefore, age may be used as an indication for surgical removal of ILTM, as the risk of surgical morbidity also increases as age increases (8). On the other hand, our finding of a higher incidence of pathological changes among patients under age 25 conflicts with our finding that the likelihood of cystic change is independent of tooth development. This inconsistency may be ascribed to the higher number of individuals aged 20-30 among the participants in our study and previous studies.

In our study, vertical and mesioangularly inclined molars showed a greater tendency toward pathological change. The association between the angular positioning of ILTMs and pathology has been reported by many authors; however, the findings among studies are contradictory. Whereas Baykul et al. (8) reported higher rates of pathological changes among vertically positioned teeth and Yildirim et al. (9) reported higher rates among both vertically and mesioangularly positioned teeth, Knutsson et al. (12) and Eliasson et al. (27) reported higher rates among horizontally positioned teeth. This suggests that factors other than those examined may play a role in the emergence of ILTM pathology. Differences in findings may also be related to differences in inclusion criteria among studies. Whereas Baykul and Knutsson et al.'s studies $(8,12)$ evaluated only third molars covered either partially or totally by mucosa, our study and Yildirim et al.'s study (9) analyzed only fully impacted third molars.

In agreement with Werkmeister et al. (28), who reported a relationship between impaction level and severe complications in impacted lower third molars, our study found a strong correlation between depth of im-

Table 3. Histopathological changes in follicular tissue of the third molars with radiographically normal.

\begin{tabular}{|l|c|c|c|}
\hline \multirow{2}{*}{ Cases } & \multirow{2}{*}{$\begin{array}{c}\text { Age range } \\
\text { (mean) }\end{array}$} & \multicolumn{2}{c|}{$\begin{array}{c}\text { \% in pathological } \\
\text { conditions }\end{array}$} \\
\cline { 3 - 4 } & & Cyst & Inflammation \\
\hline Saravana and Subhashraj (4) & $18-44(28)$ & 46 & - \\
\hline Cabbar et al. (5) & $16-69(28.2)$ & - & 33 \\
\hline Rakprasitkul (6) & $13-63(26)$ & 51 & 4.8 \\
\hline Adelsperger et al. (7) & $15-34(18.9)$ & 34 & - \\
\hline Baykul et al.(8) & $14-45(21.1)$ & 50 & - \\
\hline Yildirım et al. (9) & $15-68(24.7)$ & 23 & - \\
\hline
\end{tabular}


paction and the prevalence of pathological changes in DF follicular tissue. In terms of coverage, whereas our study found pathological changes in $11.3 \%$ of third molars completely covered by mucosa and $51.3 \%$ of those completely covered by bone tissue, Knutsson et al. (12) reported that $19.34 \%$ of pathological third molars were completely covered by mucosa, compared to only $2.55 \%$ that were covered by bone tissue.

In our study, a direct correlation emerged between ILTM development and cell activity. The increase in cell activity with development may be related to the increases in inflammation also found in this study. De Paula et al. (29) suggested that chronic inflammation may cause chronic irritation and stimulate the proliferation of epithelial cells. Edamatsu et al. (30) suggested a possible direct correlation between severity of inflammation and proliferation, and they theorized that inflammatory changes could reorder the cell turnover of DF epithelial components. In line with this suggestion, Edamatsu et al. (30) and Cabbar et al. (5) reported high levels of Ki67 and MCM-2 cell proliferation markers in dental follicles with inflammation.

\section{Conclusion}

Within the limits of the study population and method, our findings show that radiographic analysis may not be a reliable technique for the evaluation of DF. Although clinically and radiographically asymptomatic, impacted third molars-especially those in Class B that are entirely covered by mucosa and that have completed development - have the potential to undergo pathological change. For this reason, we recommend monitoring all third molars regardless of whether or not they are symptomatic. Furthermore, we recommend that histopathological analysis be conducted on all surgically extracted follicle tissue.

\section{References}

References with links to Crossref - DOI

1. De Oliveira DM, de Souza Andrade ES, da Silveira MM, Camargo IB. Correlation of the radiographic and morphological features of the dental follicle of third molars with incomplete root formation. Int $\mathbf{J}$ Med Sci. 2008;5:36-40.

2. Lautenschläger Gde A, Gallina MC, Ferreira Júnior O, Lara VS. Primary failure of tooth eruption associated with secondarily inflamed dental follicle: inflammatory follicular cyst? Braz Dent J. 2007;18:144-7.

3. Kim J, Ellis GL. Dental follicular tissue: misinterpretation as odontogenic tumors. J Oral Maxillofac Surg. 1993;51:762-7.

4. Saravana GH, Subhashraj K. Cystic changes in dental follicle associated with radiographically normal impacted mandibular third molar. Br J Oral Maxillofac Surg. 2008;46:552-3.

5. Cabbar F, Güler N, Comunoğlu N, Sençift K, Cöloğlu S. Determination of potential cellular proliferation in the odontogenic epithelia of the dental follicle of the asymptomatic impacted third molars. J Oral Maxillofac Surg. 2008;66:2004-11.

6. Rakprasitkul S. Pathologic changes in the pericoronal tissues of unerupted third molars. Quintessence Int. 2001;32:633-8.

7. Adelsperger J, Campbell JH, Coates DB, Summerlin DJ, Tomich CE. Early soft tissue pathosis associated with impacted third molars without pericoronal radiolucency. Oral Surg Oral Med Oral Pathol Oral Radiol Endod. 2000;89:402-6.

8. Baykul T, Saglam AA, Aydin U, Başak K. Incidence of cystic changes in radiographically normal impacted lower third molar follicles. Oral Surg Oral Med Oral Pathol Oral Radiol Endod. 2005;99:542-5.

9. Yildirim G, Ataoğlu H, Mihmanli A, Kiziloğlu D, Avunduk MC. Pathologic changes in soft tissues associated with asymptomatic impacted third molars. Oral Surg Oral Med Oral Pathol Oral Radiol Endod. 2008;106:14-8.

10. Adeyemo WL. Do pathologies associated with impacted lower third molars justify prophylactic removal? A critical review of the literature. Oral Surg Oral Med Oral Pathol Oral Radiol Endod. 2006;102:448-52.

11. Mesgarzadeh AH, Esmailzadeh H, Abdolrahimi M, Shahamfar M. Pathosis associated with radiographically normal follicular tissues in third molar impactions: a

clinicopathological study. Indian J Dent Res. 2008;19:208-12.

12. Knutsson K, Brehmer B, Lysell L, Rohlin M. Pathoses associated with mandibular third molars subjected to removal. Oral Surg Oral Med Oral Pathol Oral Radiol Endod. 1996;82:10-7.

13. Polat HB, Ozan F, Kara I, Ozdemir H, Ay S. Prevalence of commonly found pathoses associated with mandibular impacted third molars based on panoramic radiographs in Turkish population. Oral Surg Oral Med Oral Pathol Oral Radiol Endod. 2008;105:e41-7.

14. Nordenram A. Positional relationships of the impacted $3 \mathrm{~d}$ molar (classification of 1179 cases in an oral-surgical remitted material. Sven Tandlak Tidskr. 1966;59:591-600.

15. Shiller WR. Positional changes in mesio-angular impacted mandibular third molars during a year. J Am Dent Assoc. 1979;99:460-4.

16. Köhler S, Schmelzle R, Loitz C, Püschel K. Development of wisdom teeth as a criterion of age determination. Ann Anat. 1994;176:339-45.

17. Gleiser I, Hunt EE Jr. The permanent mandibular first molar: its calcification, eruption and decay. Am J Phys Anthropol. 1955;13:25383.

18. Doğan N, Orhan K, Günaydin Y, Köymen R, Okçu K, Uçok O. Unerupted mandibular third molars: symptoms, associated pathologies, and indications for removal in a Turkish population. Quintessence Int. 2007;38:e497-505.

19. Punwutikorn J, Waikakul A, Ochareon P. Symptoms of unerupted mandibular third molars. Oral Surg Oral Med Oral Pathol Oral Radiol Endod. 1999;87:305-10.

20. Van der Linden W, Cleaton-Jones P, Lownie M. Diseases and lesions associated with third molars. Review of 1001 cases. Oral Surg Oral Med Oral Pathol Oral Radiol Endod. 1995;79:142-5.

21. Obiechina AE, Arotiba JT, Fasola AO. Third molar impaction: evaluation of the symptoms and pattern of impaction of mandibular third molar teeth in Nigerians. Odontostomatol Trop. 2001;24:22-5.

22. Güven O, Keskin A, Akal UK. The incidence of cysts and tumors around impacted third molars. Int J Oral Maxillofac Surg. 2000;29:131-5.

23. Shear M, Singh S. Age-standardized incidence rates of ameloblastoma and dentigerous cyst on the Witwatersrand, South Africa. Community Dent Oral Epidemiol. 1978;6:195-9.

24. Sağlam AA, Tüzüm MS. Clinical and radiologic investigation of the incidence, complications, and suitable removal times for fully impacted teeth in the Turkish population. Quintessence Int. 2003;34:53-9.

25. Ventä I. Predictive model for impaction of lower third molars. Oral Surg Oral Med Oral Pathol. 1993;76:699-703.

26. Miller CS, Bean LR. Pericoronal radiolucencies with and without radiopacities. Dent Clin North Am. 1994;38:51-61.

27. Eliasson S, Heimdahl A, Nordenram A. Pathological changes related to long-term impaction of third molars. A radiographic study. Int J Oral Maxillofac Surg. 1989;18:210-2.

28. Werkmeister R, Fillies T, Joos U, Smolka K. Relationship between lower wisdom tooth position and cyst development, deep ab- 
scess formation and mandibular angle fracture. J Craniomaxillofac Surg. 2005;33:164-8.

29. De Paula AM, Carvalhais JN, Domingues MG, Barreto DC, Mesquita RA. Cell proliferation markers in the odontogenic keratocyst: effect of inflammation. J Oral Pathol Med. 2000;29:477-82.

30. Edamatsu M, Kumamoto H, Ooya K, Echigo S. Apoptosis-related factors in the epithelial components of dental follicles and dentigerous cysts associated with impacted third molars of the mandible. Oral Surg Oral Med Oral Pathol Oral Radiol Endod. 2005;99:17-23.

\section{Acknowledgements}

The authors thank to Dr. Armağan Hayırlı for his assistance in statistical evaluation of the data.

*This study was presented at the 4rd. International Oral and Maxillofacial Surgery Society Congress, Antalya, 2010. 